\title{
Characterization of thermal structure and conditions for overshooting of tropical and extratropical cyclones with GPS radio occultation
}

\author{
R. Biondi ${ }^{1}$, A. K. Steiner ${ }^{1}$, G. Kirchengast ${ }^{1,2}$, and T. Rieckh ${ }^{1}$ \\ ${ }^{1}$ Wegener Center for Climate and Global Change (WEGC), University of Graz, Graz, Austria \\ ${ }^{2}$ Institute for Geophysics, Astrophysics, and Meteorology/Inst. of Physics, University of Graz, Graz, Austria
}

Correspondence to: R. Biondi (riccardo.biondi@uni-graz.at)

Received: 11 March 2014 - Published in Atmos. Chem. Phys. Discuss.: 26 November 2014

Revised: 19 March 2015 - Accepted: 21 April 2015 - Published: 11 May 2015

\begin{abstract}
The thermal structure of tropical cyclones (TCs) in different ocean basins is studied using global positioning system (GPS) radio occultation (RO) measurements co-located with TCs' best tracks. The objective of this work is to understand the mutual influence of TCs and atmospheric parameters in different regions. We selected more than 20000 GPS RO profiles co-located with TCs in a time window of $6 \mathrm{~h}$ and space window of $600 \mathrm{~km}$ from the TC center in the period 2001-2012 and classified them by intensity of the cyclone and by ocean basin. The results show that TCs have different characteristics depending on the basin, which affects the cloud top altitude and the TC thermal structure which usually shows a negative temperature anomaly near the cloud top altitude. In the Northern Hemisphere ocean basins, the temperature anomaly becomes positive above the cloud top while in the Southern Hemisphere ocean basins it stays negative up to about $25 \mathrm{~km}$ in altitude.

Furthermore, in the Southern Hemisphere the storms reach higher cloud top altitudes than in the Northern Hemisphere ocean basins, indicating that possible overshootings overpass the climatological tropopause more deeply at extratropical latitudes. The comparison of the TC thermal structure with the respective monthly mean tropopause altitude allows for a detailed analysis of the probability for possible overshooting. While the co-locations between GPS ROs and TC tracks are well distributed in all the ocean basins, conditions for possible overshootings are found to be more frequent in the Southern Hemisphere basins and in the northern Indian Ocean basin. However, the number of possible overshootings for high intensity storms (i.e., TC categories 1-5) is the highest in the western Pacific Ocean basin.
\end{abstract}

\section{Introduction}

Tropical cyclones (TCs) are destructive events that every year cause many deaths, injuries and damage to human property and landscape. They are the natural catastrophes that account for major economic losses in several countries including the USA (Pielke et al., 2003; Emanuel, 2005). So far studies on TCs are neither able to clearly detect trends in the frequency and intensity of these phenomena nor able to understand what impact climate change could have on them (Landsea et al., 2006; Emanuel et al., 2008; Emanuel, 2013; Kunkel et al., 2013). However, it is predicted that major economic losses due to TCs may be doubled in the future (Mendelsohn et al., 2013).

TCs hit whatever they find along their path without any distinction between poor and rich countries. Recently the landfall of hurricane Sandy was considered one of the most destructive events in USA east coast history (Halverson and Rabenhorst, 2013), while typhoon Haiyan created a devastating tragedy in the Philippines (Chiu, 2013).

We are presently able to predict the track of TCs $(100$ $200 \mathrm{~km}$ error) with good accuracy within 12 to $24 \mathrm{~h}$ (Goerss, 2000; Roy and Kovordányi, 2012), but we are still far from forecasting the intensity of the storm (Emanuel, 1999; De Maria et al., 2005; Lin et al., 2013) and understanding its development (Montgomery et al., 2012).

Satellite measurements have drastically improved the TC forecast (e.g., Dvorak, 1975) and monitoring accuracy (Brueske and Velden, 2003; Demuth et al., 2004; Velden et al., 2006) by using different remote-sensing instruments on meteorological and research satellites. Further progress was 
made in the last decade by the global positioning systems (GPS) radio occultation (RO) technique (e.g., Huang et al., 2005).

Wong and Emanuel (2007), Luo et al. (2008) and Vergados et al. (2013) demonstrated that there is a connection between the cloud top height and cloud top temperature with the intensity of the storm. Biondi et al. $(2012,2013)$ showed a correlation between the cloud top altitude and the storm's thermal structure. The knowledge of the thermal structure gives important information on the cloud top height and this entails a better understanding of atmospheric circulation and troposphere-stratosphere transport, which are still poorly understood (Danielsen, 1993; Folkins and Martin, 2005).

The measurement of atmospheric parameters (such as temperature) with high vertical resolution and accuracy at the tropopause level is difficult especially during severe weather events (e.g., TCs). Polar-orbiting satellites in low-Earth orbit do not provide suitable temporal and spatial (vertical and horizontal) resolution to study mesoscale weather phenomena. Geostationary satellites have excellent horizontal and temporal resolution for this purpose, but lack precise vertical discrimination, and offer little information about the tropical or subtropical tropopause. Ground-based measurements are too sparse and often not reliable in the upper troposphere and lower stratosphere (UTLS).

Many studies have been conducted to determine the altitude of the storm cloud top height using satellite instruments and different techniques (Knibbe et al., 2000; Koelemeijer et al., 2002; Poole et al., 2002; Platnick et al., 2003; Minnis et al., 2008; Chang et al., 2010; Biondi et al., 2013), but the results depend strongly on the physical retrieval method and on the satellite data used (Sherwood et al., 2004), with errors ranging from about $400 \mathrm{~m}$ (Biondi et al., 2013) for a selected number of cases to $3 \mathrm{~km}$ (Chang et al., 2010). Some other studies have analyzed the UTLS during TCs using limb sounding measurements such as Atmospheric Infrared Sounder (AIRS) and Microwave Limb Sounder (MLS) with a vertical resolution of 2 to $3 \mathrm{~km}$ (Ray and Rosenlof, 2007).

The GPS RO technique (Kursinski et al., 1997; Anthes, 2011; Steiner et al., 2011) allows for the estimation of atmospheric temperature in remote areas and during extreme weather events with global coverage and high vertical resolution and accuracy (Steiner et al., 2013), avoiding temperature smoothing issues in the UTLS (given by microwave and infrared radiometers) and improving the poor temporal and spatial coverage given by satellite lidars, radars and balloon soundings.

The objective of this study is to analyze the thermal structure of TCs by using RO measurements for different storm intensities and different ocean basins where TCs develop. We aim to show that the RO measurements are well suited for studying severe storms and for evaluating the storms' contribution to the atmospheric circulation (Pommereau and Held, 2007; Corti et al., 2008; Romps and Kuang, 2009).
In Sect. 2 we describe the data sets used, in Sect. 3 we give a description of the methodology, and in Sect. 4 we describe the results obtained analyzing all the RO profiles co-located with TCs. In the final section, we report the conclusions highlighting the possible future developments and applications.

\section{Data description}

\subsection{Tropical cyclones' best tracks}

We have downloaded the TCs' best tracks from the International Best Track Archive for Climate Stewardship (IBTrACS; http://www.ncdc.noaa.gov/ibtracs/) (Knapp et al., 2010) in Network Common Data Form (netCDF) format. IBTrACS is a complete archive containing information about TCs all around the world combining the data acquired by several agencies responsible for different ocean basins. For all the TCs the most important characteristics are reported, including the following: TC name, date and time of acquisition (every 3 or $6 \mathrm{~h}$ depending on the agency); latitude and longitude of the TC center; source (agency data provider); wind speed (averaged over 1 or 10 min depending on the agency); and pressure.

\subsection{GPS radio occultation temperature}

We have used the GPS RO product level 2 (L2) (including refractivity, temperature and pressure) processed by the Wegener Center for Climate and Global Change (WEGC) through the new occultation processing system (OPS) version 5.6 based on University Corporation for Atmospheric Research (UCAR) version 2010.2640 orbit and excess phase data (Schwaerz et al., 2013). The WEGC OPSv5.6 is based on a geometrics optics retrieval combined with a wave optics retrieval in the lower and middle troposphere. A bending angle optimization is performed at high altitudes with colocated short-range forecast profiles of the European Centre for Medium-Range Weather Forecasts (ECMWF).

The vertical resolution ranges from about $100 \mathrm{~m}$ in the lower troposphere to about $1 \mathrm{~km}$ in the stratosphere (Gorbunov et al., 2004; Kursinski et al., 1997). The horizontal resolution is about $1.5 \mathrm{~km}$ across ray and ranges from about 60 to about $300 \mathrm{~km}$ along ray (Melbourne et al., 1994; Kursinski et al., 1997).

Physical temperature is retrieved based on an optimal estimation retrieval with co-located ECMWF short-term forecast profiles as background data (the latter contribute relevant information in the middle and lower troposphere). For the present study of TCs we use the OPSv5.6 physical temperature profiles.

From this OPSv5.6 archive, we use data from the following missions: the Satélite de Aplicaciones Scientíficas C (SAC-C) from 2001 to 2011 (Hajj et al., 2004), the Challenging Minisatellite Payload (CHAMP) from 2001 to 2008 (Wickert et al., 2001), the Gravity Recovery And Climate 
Experiment A (GRACE-A) from 2007 to 2012 (Beyerle et al., 2005), the Constellation Observing System for Meteorology, Ionosphere and Climate (COSMIC) from 2006 to 2012 (Anthes et al., 2008). In order to have a suitable mean reference field available against which anomalies can be defined, we have created a GPS RO temperature reference climatology averaging all the GPS RO profiles collected in the period 2001 to 2012 from the different missions to monthly means for a $5^{\circ} \times 5^{\circ}$ horizontal resolution. The climatology is finally provided at a vertical sampling grid of $100 \mathrm{~m}$ and at a horizontal grid sampled at $1^{\circ} \times 1^{\circ}$ in longitude and latitude and it will be denoted in the following sections as $T_{\text {clim }}$.

\section{Methods}

\subsection{Tropopause altitudes}

Tropopause altitudes were computed from individual RO temperature profiles (Rieckh et al., 2014), using the lapse rate definition of the World Meteorological Organization (WMO, 1957). This definition allows for finding multiple tropopauses, which was a requirement for this study. The WMO states that

1. "The first tropopause is defined as the lowest level at which the lapse rate decreases to $2^{\circ} \mathrm{C} \mathrm{km}^{-1}$ or less, provided also the average lapse rate between this level and all higher levels within $2 \mathrm{~km}$ does not exceed $2{ }^{\circ} \mathrm{C} \mathrm{km}^{-1}$."

2. "If above the first tropopause the average lapse rate between any level and all higher levels within $1 \mathrm{~km}$ exceeds $3{ }^{\circ} \mathrm{C} \mathrm{km}^{-1}$, then a second tropopause is defined by the same criterion as under (1). This tropopause may be within or above the $1 \mathrm{~km}$ layer."

An example of tropopause altitudes as a function of latitude is shown in Fig. 1 with about 60000 cases in January 2007 (a) and in July 2007 (b): the tropopause has a seasonal variability with higher altitudes during the Northern Hemisphere winter (Rieckh et al., 2014).

We finally computed monthly mean tropopause altitudes based on the individual tropopause altitudes for each month and for zonal means of 10-degree width in latitude. Cloud top altitudes were then compared to mean tropopause altitudes ( \pm standard deviation) for the detection of possible overshootings into the stratosphere.

\subsection{Tropical cyclone cloud top height}

The mean GPS RO latitude and longitude tangent points were co-located with the TCs' center coordinates in a time window of $6 \mathrm{~h}$ and a space window of $600 \mathrm{~km}$ (Table 1), leading to more than 20000 collocation cases. The RO profiles were also sub-selected, for checking the sensitivity to selection criteria, in a shorter time window (of 3 and $1 \mathrm{~h}$ ) and in a smaller
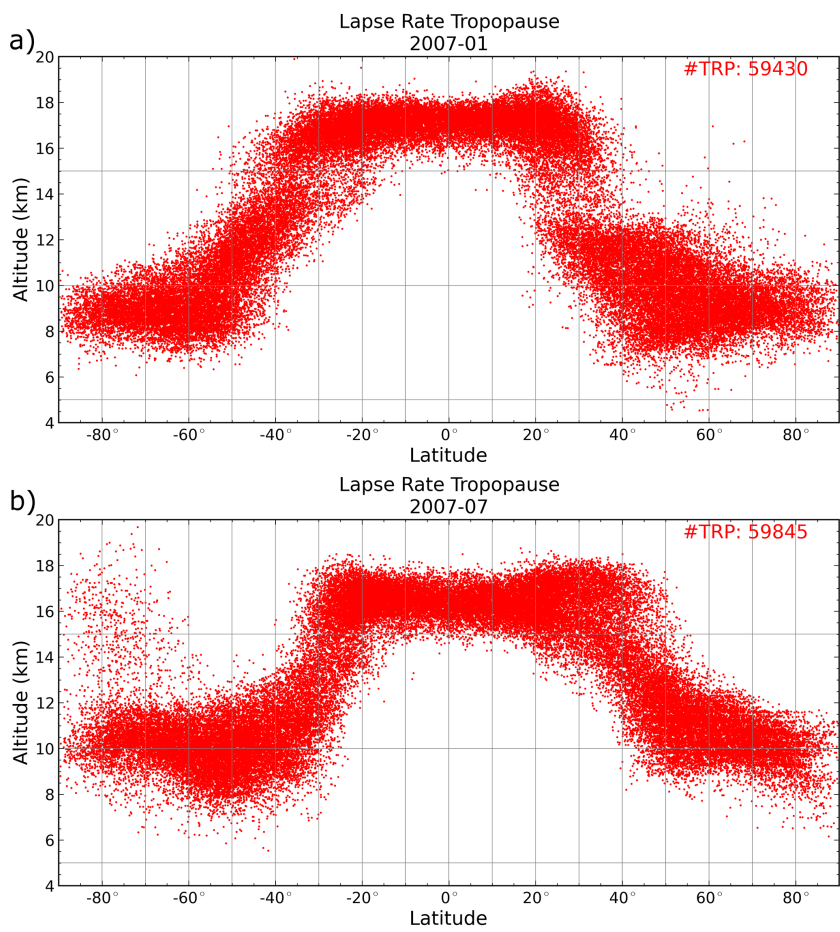

Figure 1. Exemplary tropopause altitude distribution vs. latitude during the Northern Hemisphere winter (a) and summer (b).

Table 1. Number of RO profiles co-located with TCs within increasing distance from the center of the TC.

\begin{tabular}{lr}
\hline $\begin{array}{l}\text { Distance from the } \\
\text { TC center }[\mathrm{km}]\end{array}$ & $\begin{array}{r}\text { Number } \\
\text { of RO }\end{array}$ \\
\hline $0-30$ & 47 \\
$30-100$ & 503 \\
$100-200$ & 1579 \\
$200-300$ & 2603 \\
$300-400$ & 3674 \\
$400-500$ & 4949 \\
$500-600$ & 7223
\end{tabular}

space window of $300 \mathrm{~km}$. The results were found consistent with the larger data set $(6 \mathrm{~h}$ and $600 \mathrm{~km})$, which we finally used in this study, allowing for a larger number of samples for more robust statistics.

We investigated different ocean basins as shown in Fig. 2: North Atlantic Ocean (NA), eastern Pacific Ocean (EP), western Pacific Ocean (WP), South Pacific Ocean (SP), northern Indian Ocean (NI) and southern Indian Ocean (SI). For any ocean basin the profiles were classified (Table 2) using a common storm intensity scale (tropical depression (TD), tropical storm (TS), TC categories 1-5) given by the Saffir-Simpson Hurricane wind scale.

Due to the large dimensions of a TC and its relatively slow horizontal movement, it is possible that the same RO profile is selected more than once with different temporal and spatial 


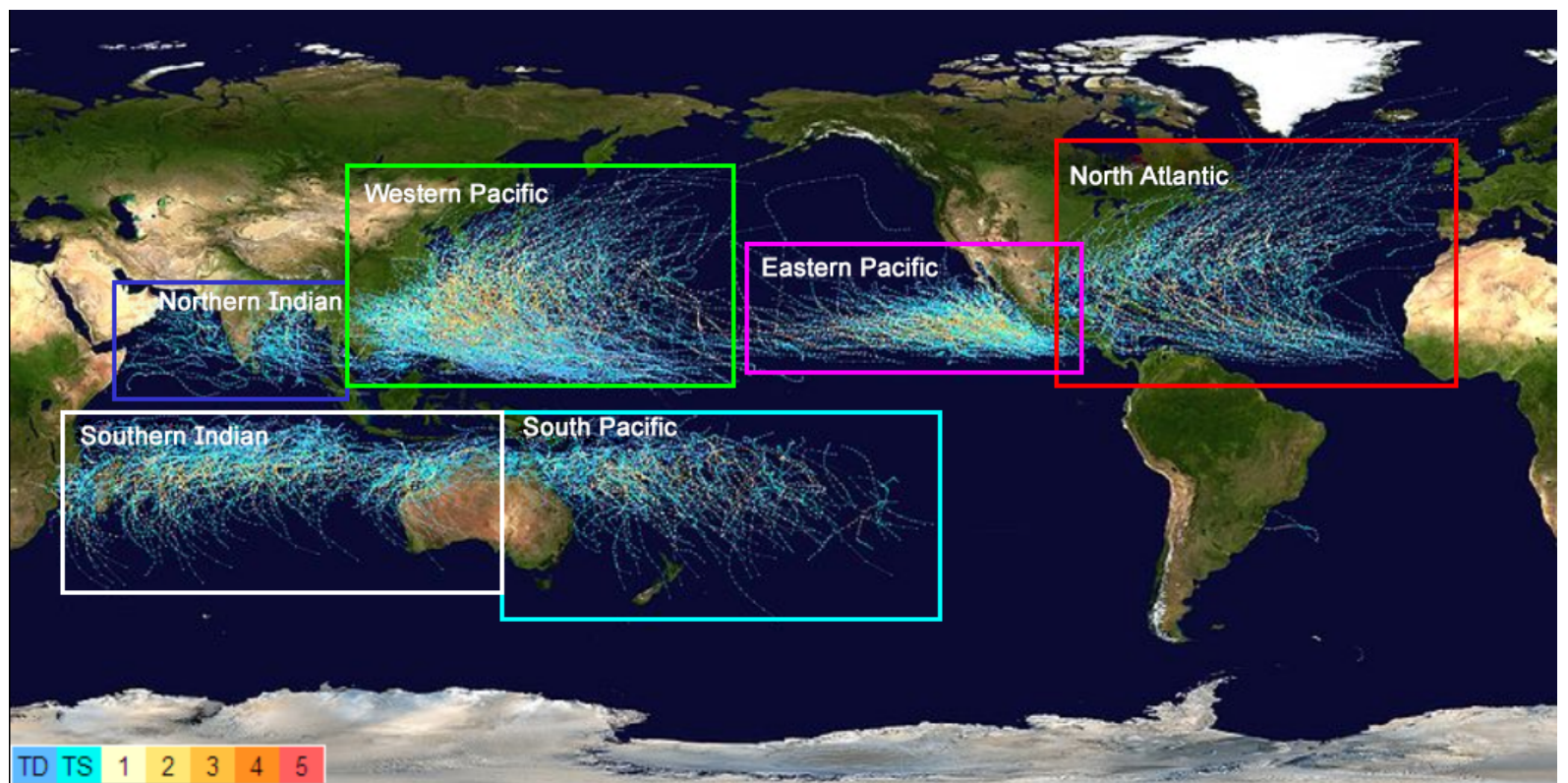

Figure 2. Illustration of TC tracks (background from Wikipedia) for ocean basins: North Atlantic Ocean (red), eastern Pacific Ocean (magenta), western Pacific Ocean (green), South Pacific Ocean (cyan), northern Indian Ocean basin (blue) and southern Indian Ocean basin (white).

Table 2. Mean altitude (in $\mathrm{km}$ ) of the lowest coldest point of temperature anomaly profiles for different ocean basins and different storm intensities. The Southern Hemisphere ocean basins are marked in italic.

\begin{tabular}{lrrrrrrr}
\hline & TD & TS & Cat1 & Cat2 & Cat3 & Cat4 & Cat5 \\
\hline NA & 15.4 & 15.5 & 15.9 & 16 & 16 & 16.2 & 14.4 \\
WP & 15.6 & 16.3 & 16.3 & 16.4 & 16.4 & 16.5 & 17.2 \\
EP & 15.6 & 15.7 & 15.7 & 15.8 & 16 & 15.9 & 15.1 \\
SP & 17.8 & 17.7 & 17.8 & 17.4 & 17.6 & 17.4 & 17.9 \\
NI & 16.6 & 16.6 & 17.7 & 16.3 & 17.5 & 17.4 & 17 \\
SI & 17.5 & 17.9 & 17.4 & 17.7 & 17.3 & 16.7 & 17.8 \\
\hline
\end{tabular}

NA is North Atlantic Ocean; WP is western Pacific Ocean; EP is eastern Pacific Ocean; SP is South Pacific Ocean; NI is northern Indian Ocean; SI is southern Indian Ocean. TD is tropical depression; TS is tropical storm; Cat1 is tropical cyclone category-1; Cat2 is tropical cyclone category-2; Cat 3 is tropical cyclone category-3; Cat4 is tropical cyclone category-4; Cat5 is tropical cyclone category-5.

distances from the TC center. In these cases we have included only the co-located RO profile with the shortest delay.

For any ocean basin and for each storm category, we have sampled the RO profiles around the storm center as shown in Fig. 3, where we show the distribution of GPS RO profiles within 6 and $3 \mathrm{~h}$ around the center of tropical storms in the North Atlantic Ocean basin. In Fig. 4 we show the distribution of the same profiles along the real tracks in latitude and longitude.

For each ocean basin and each storm category we computed the temperature anomaly $\left(T_{\text {anomaly }}\right)$ of any single RO profile comparing the temperature during the storm $\left(T_{\text {storm }}\right)$

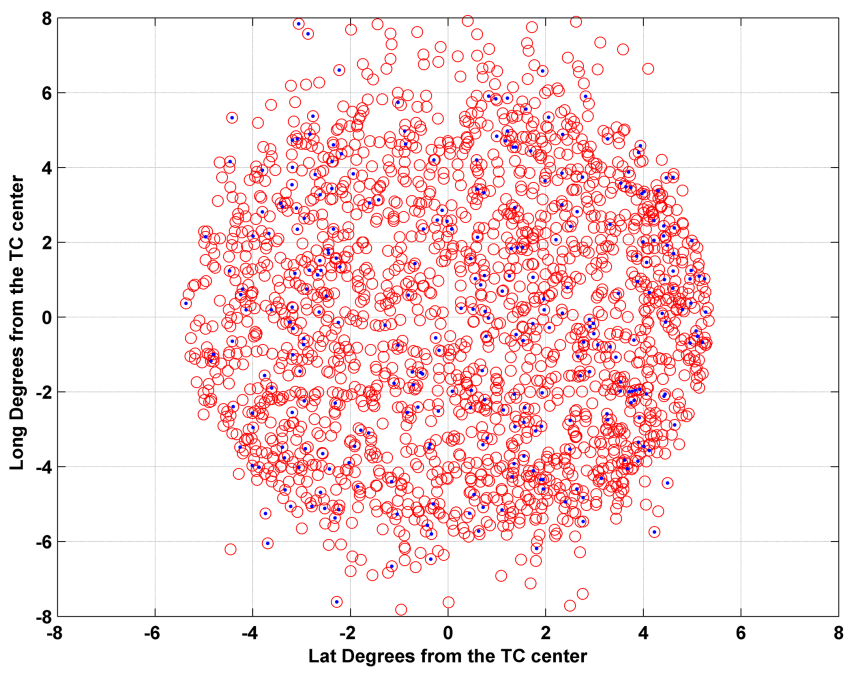

Figure 3. Exemplary distribution of GPS RO profiles within $6 \mathrm{~h}$ (red circles) and $3 \mathrm{~h}$ (blue dots) around the center of a tropical storm in the North Atlantic Ocean, within a spatial window of $600 \mathrm{~km}$ from the center.

with the local monthly mean climatology $\left(T_{\text {clim }}\right)$ as defined in Sect. 2.2 (i.e., in the respective $1^{\circ} \times 1^{\circ}$ bin):

$T_{\text {anomaly }}=T_{\text {storm }}-T_{\text {clim }}$

We finally averaged all the profiles in the same ocean basin for each storm category to be able to compare the thermal structure characterizing the basin itself. 


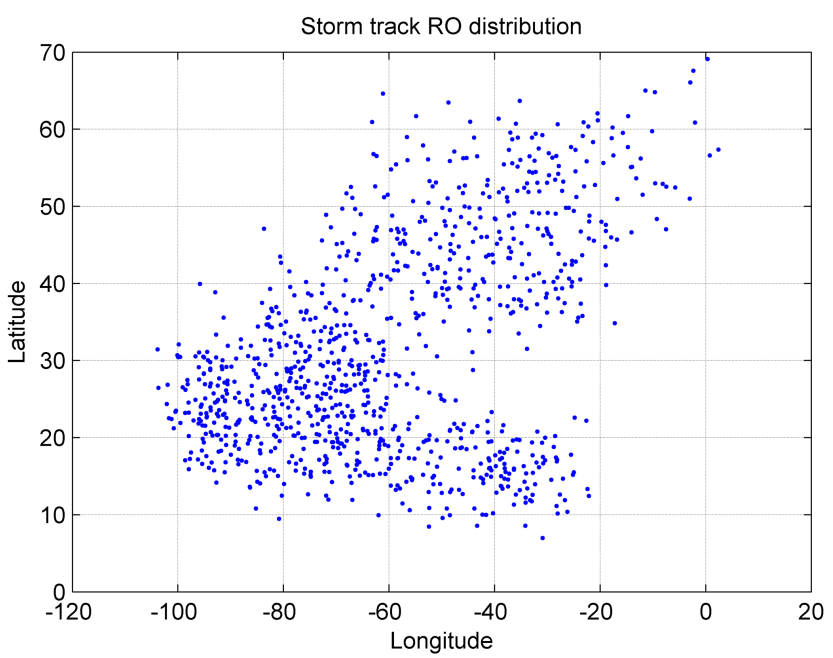

Figure 4. Exemplary distribution of GPS RO profiles in a time window of $6 \mathrm{~h}$ and spatial window of $600 \mathrm{~km}$ along 135 tropical storm tracks in the North Atlantic Ocean basin.

In all the ocean basins, the TCs often move from the tropics to extratropical areas (especially in the North Atlantic Ocean and the western Pacific Ocean). We categorized the profiles as "tropical" between $20^{\circ} \mathrm{S}$ and $20^{\circ} \mathrm{N}$ and as "extratropical" beyond $20^{\circ}$ latitude as shown in Table 2, for highlighting the different thermal structures with the variation of latitude.

For monitoring possible overshooting conditions during a storm, we computed the height of the lowest anomaly minimum $\left(H_{\text {coldest }}\right)$ between 10 and $22 \mathrm{~km}$ in altitude for each $T_{\text {anomaly }}$ profile (Biondi et al., 2013), the monthly mean tropopause altitude $\left(H_{\mathrm{mm} \_ \text {trop }}\right)$ of the respective month and area (Sect. 3.1), and the corresponding standard deviation of the monthly mean tropopause altitude $\left(H_{\text {mstd_trop }}\right)$. We used the multi-annual standard deviation estimate for each month of the year here (e.g., October 2001 to 2012 data for October; sensitivity testing showed that using standard deviation estimates for individual months leads to essentially the same results).

For robustness, we used two different references for detecting the possible overshooting conditions:

$$
\begin{aligned}
& H_{\text {coldest }}>H_{\mathrm{mm}_{\_} \text {trop }}+H_{\mathrm{mstd} \_ \text {trop }}, \\
& H_{\text {coldest }}>H_{\mathrm{mm}_{-} \text {trop }}+H_{\mathrm{mstd} \_ \text {trop }}+1.0 \mathrm{~km},
\end{aligned}
$$

where $1.0 \mathrm{~km}$ is the uncertainty for TC cloud top altitude detection using GPS RO as estimated by Biondi et al. (2013) from analysis with co-located lidar data. The uncertainty occurs mainly due to the finite resolution of RO data (see Sect. 2.2), and also due to co-location uncertainty, whereas the RO geopotential height and hence altitude allocation error is only about $10 \mathrm{~m}$ in the troposphere and around the tropopause within the $50^{\circ} \mathrm{S}$ and $50^{\circ} \mathrm{N}$ latitude band of interest here (Scherllin-Pirscher et al., 2011). If $H_{\text {coldest }}$ satisfies

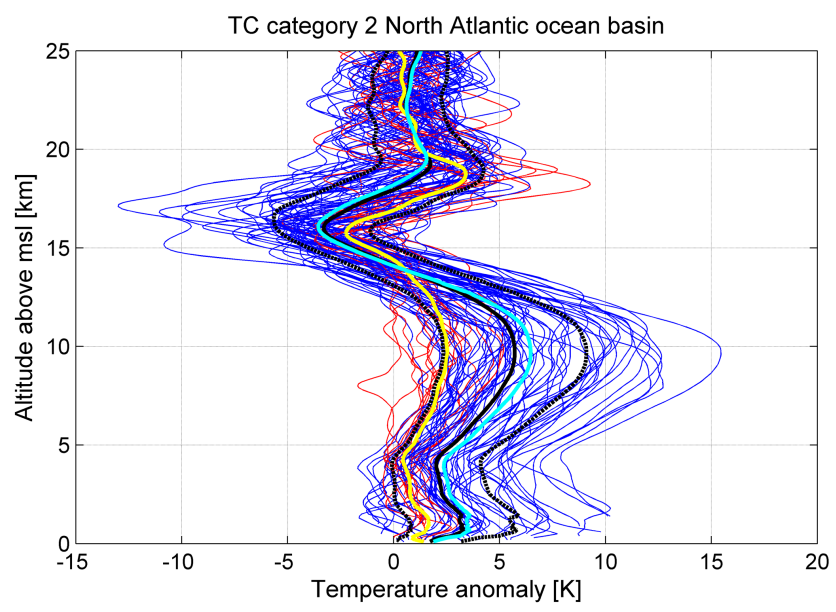

Figure 5. RO temperature anomaly profiles during TC category 2 in the North Atlantic Ocean basin. In red the tropical profiles, in blue the extratropical profiles, in yellow the mean anomaly of tropical profiles, in light-blue the mean anomaly of extratropical profiles, in black the mean of all the profiles and dashed black the mean plus/minus the standard deviation.

Eq. (2) it is considered to be indicative of possible overshooting when the lowest anomaly minimum (the cloud top) overpasses the tropopause monthly mean altitude plus its standard deviation. Equation (3) defines an even more robust condition where $H_{\text {coldest }}$ is considered to be indicative of possible overshooting when the lowest anomaly minimum (the cloud top) overpasses the tropopause monthly mean altitude plus its standard deviation plus the $1 \mathrm{~km}$ uncertainty margin.

We have used these two different thresholds, one less and one more conservative, for detecting the possible overshooting because there is still a large uncertainty in the atmospheric physics community in the overshooting detection. Equation (2) should be already accurate enough due to the temperature accuracy of GPS RO, but with Eq. (3) we want to take into account also the uncertainty of the technique used for detecting the TC cloud top altitude (Biondi et al., 2013). Since there is not enough independent reference data available for validating the results at this point, we report both results and do not advocate a more exact definition based on our current knowledge.

\section{Results}

\subsection{Thermal structure}

The temperature anomaly during TCs usually shows a tropospheric warming and a sharp inversion just below the cloud top with a cooling corresponding to the cloud top altitude (Biondi et al., 2012, 2013). With reference to these results, we assume that the storm cloud top altitude corresponds to $H_{\text {coldest }}$. However, we note possible uncertainties regarding the cooling signature which may also be due to the presence 

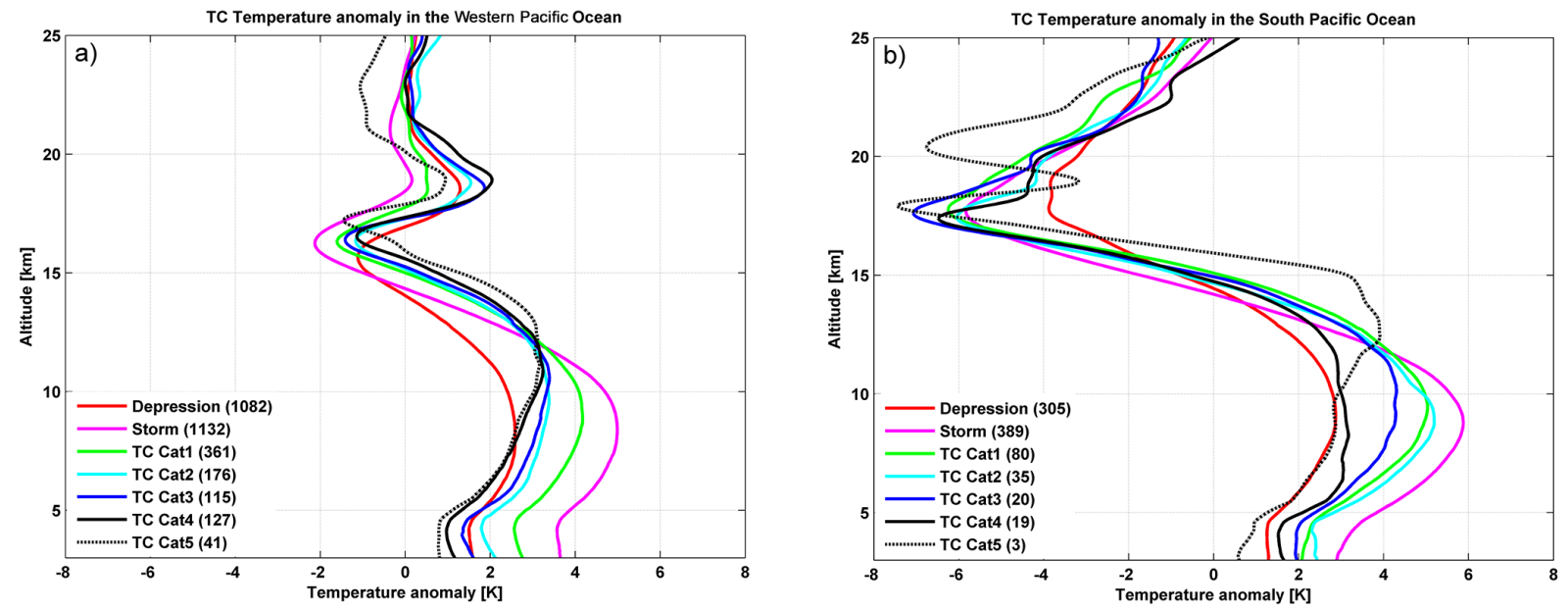

Figure 6. Mean temperature anomalies for different storm categories shown for: (a) western Pacific Ocean and (b) South Pacific Ocean. Numbers in brackets denote the numbers of observations.

of large-scale dynamical response to latent heating below the cold anomaly (Randel et al., 2003; Holloway and Neelin, 2007 ) or to gravity waves originated from the TC (Tsuda et al., 2000; Kiladis et al., 2001; Kim and Alexander, 2015).

As shown in Fig. 5, this behavior is in general similar for TCs in the tropical and extratropical areas, but in the extratropical area the amplitudes of tropospheric warming and cloud top cooling are amplified. In Fig. 5 we show as an example the $84 \mathrm{RO}$ profiles (69 extratropical and 15 tropical) of a TC category 2 in the North Atlantic Ocean basin. The temperature anomaly profiles at the storm's location are computed relative to the monthly mean temperature climatology (2001 to 2012) for the respective location $\left(1^{\circ} \times 1^{\circ}\right.$ bin). The same feature is evident in all the other ocean basins for all the categories (not shown). The mean temperature anomaly for tropical profiles (yellow line) reaches a maximum of about $2.5 \mathrm{~K}$ at about $10 \mathrm{~km}$ in altitude and a minimum of about $-2.5 \mathrm{~K}$ near $16 \mathrm{~km}$ in altitude. The mean temperature anomaly for extratropical profiles (light-blue line) shows the same features but more pronounced with a maximum of about $6 \mathrm{~K}$ and a minimum of about $-4 \mathrm{~K}$.

Figure 6 shows mean temperature anomaly profiles for the western Pacific Ocean basin and the South Pacific Ocean basin, respectively, for all storm categories as representative of the two hemispheres. Overall during a TC, the troposphere is warmer than the climatological mean and the cloud top is colder. In the Northern Hemisphere above the altitude $H_{\text {coldest }}$ there is a warming in the stratosphere, which is not well present in the Southern Hemisphere.

Figure 7 gives an overview of the minimum temperature anomaly vs. altitude of the coldest point for all ocean basins and storm categories. TDs and TSs usually reach the coldest point at lower altitudes (4 basins out of 6) and the TCs in categories 4 and 5 reach the coldest point at higher altitudes. No relevant differences can be highlighted for the storm cat-

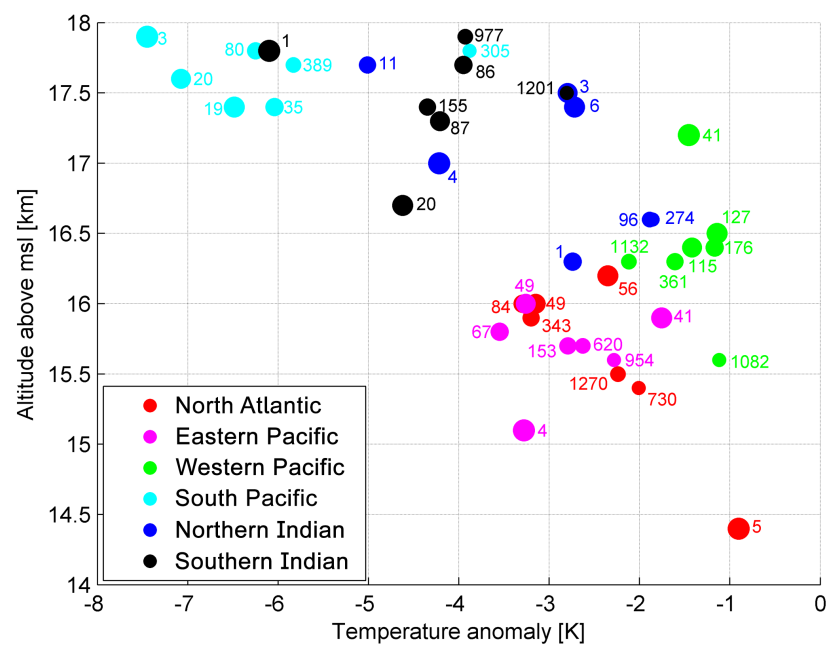

Figure 7. Temperature anomaly vs. altitude of the coldest point for different ocean basins and different storm intensities. The colors denote different basins. The circle size denotes different intensities and increases with intensity, from the smallest to the biggest, in the following order: TD-TS-Cat1-Cat2-Cat3-Cat4-Cat5. The numbers represent the case number used for the analyses.

egories 1, 2 and 3. The coldest anomalies are found in the South Pacific for all storm categories: between -8 and $-6 \mathrm{~K}$ for TCs, between -6 and $-5 \mathrm{~K}$ for TSs and about $-4 \mathrm{~K}$ for TDs. For this area, the $H_{\text {coldest }}$ also is at higher altitudes (between 17.4 and $17.9 \mathrm{~km}$ ) than in any other basin (Table 2). Temperature anomalies over the southern Indian Ocean are also usually colder than in the other ocean basins (except South Pacific), with higher $H_{\text {coldest }}$. In the Southern Hemisphere the storms reach higher altitudes than in the Northern Hemisphere (Table 2) and they also have colder cloud tops.

Another feature characteristic of storms is the double tropopause (Danielsen, 1993; Corti et al., 2008; Biondi et al., 
2012, 2013; Davis et al., 2014), which is visible in Fig. 6b for TC category 5 (dotted lines). This is also apparent for all the TC categories in the northern Indian Ocean basin (not shown), since the small number of cases does not smooth the double variation such as it happens for the other ocean basins and categories.

\subsection{Tropopause uplift and possible overshooting}

The overshooting due to convective systems and TCs is an important topic for understanding the atmospheric circulation and the climate changes (Pommereau and Held, 2007; Romps and Kuang, 2009), but it is still debated due to the difficulties of measuring atmospheric parameters during severe events. Using the definition of possible overshooting conditions given by Eqs. (2) and (3), we compared any single anomaly temperature profile with the corresponding zonal monthly mean tropopause altitude, computed for latitude bands with 10-degree width, obtaining the results reported in Tables 3 and 4. Table 3 reports the details for each ocean basin and each storm category distinguishing between events in the tropical or extratropical area. Table 4 gives a summary.

As already described in Sect. 3.2 and following the findings of Biondi et al. $(2012,2013)$, we assume that the lowest temperature anomaly minimum corresponds to the TC cloud top altitude and the cyclone's strong convection causes the local tropopause uplift. According to this theory the TC creates a double tropopause where the primary tropopause is due to the presence of the TC's cloud top and the secondary tropopause is the former tropopause which is pushed up by the convection (Biondi et al., 2012, 2013).

In Table 3 it is evident that the number of possible overshootings obtained by using Eq. (3) is much lower (about one third) than the number obtained by using Eq. (2), as should be expected from the former threshold criterion being more conservative. However, the distribution of the possible overshootings over the ocean basins is the same (not shown), but with a reduced number of cases from Eq. (3), so the same considerations done hereafter for Table 3 and Fig. 8 are also valid for possible overshootings computed with Eq. (3).

Figure 8 shows the distribution map of co-locations between GPS RO and TC tracks for different intensities. Figure 9 shows the distribution map of possible overshootings detected using Eq. (2). The area with the highest overshooting probability from strong cyclones is found to be the western Pacific Ocean. Our results are consistent with the overshooting patterns reported by Romps and Kuang (2009) with only a small difference in the eastern Pacific Ocean basin, where we do not see too many overshooting conditions. The comparison between Figs. 8 and 9 highlights the presence of strong cyclones in all ocean basins including the North Atlantic Ocean and eastern Pacific Ocean basins, but the occurrence of possible overshootings is much lower in these basins than in the western Pacific Ocean and southern Indian Ocean basins.

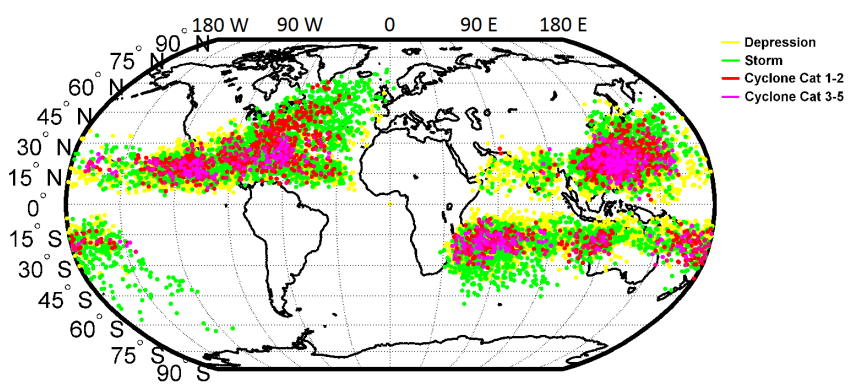

Figure 8. Distribution map of GPS RO co-located with storms of different categories: tropical depression (yellow), tropical storm (green), tropical cyclone categories 1 and 2 (red) and tropical cyclone categories 3 to 5 (magenta).

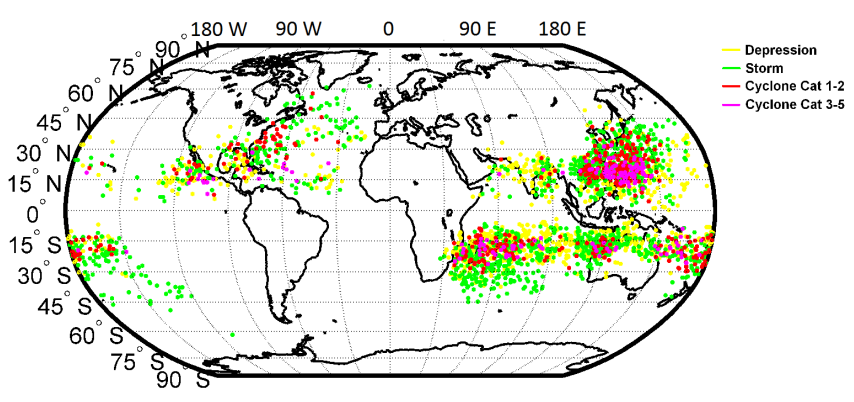

Figure 9. Distribution of possible overshootings for different storm categories: tropical depression (yellow), tropical storm (green), tropical cyclone categories 1 and 2 (red) and tropical cyclone categories 3 to 5 (magenta).

The results show that in general conditions for possible overshootings into the stratosphere are found more often in the tropics $(26.8 \%)$ than in the extratropics $(13.5 \%)$. In the Southern Hemisphere, possible overshootings are more frequent $38.9 \%$ of tropical cases and $25 \%$ of extratropical cases) than in the Northern Hemisphere $(20.2 \%$ of tropical cases and $9.9 \%$ of extratropical cases). The possible overshootings mostly come from tropical cases with high intensity storms. The lowest percentage of possible overshooting conditions is detected in the eastern Pacific Ocean area $(6.3 \%$ for tropical cases and just $6.6 \%$ of extratropical cases). The highest percentage is detected in the South Pacific Ocean area with $40.9 \%$ of tropical cases and $48.4 \%$ of extratropical cases. It is also high in the Indian Ocean with 34.5 and $38.3 \%$ in the northern and southern tropics, respectively, and 46.6 and $40.1 \%$ in the northern and southern extratropics, respectively (in this case the number of colocations is very small). We do not give any detail on the statistics by intensity, since the number of cases for higher intensities (i.e., categories 3 to 5) is too small.

The monthly mean tropopause altitudes in the tropics between $20^{\circ} \mathrm{S}$ and $20^{\circ} \mathrm{N}$ ranges between 16 and $17.5 \mathrm{~km}$ altitude depending on the season. In the extratropics between 20 and $30^{\circ}$ latitude it is about $1 \mathrm{~km}$ lower, and exhibits higher 


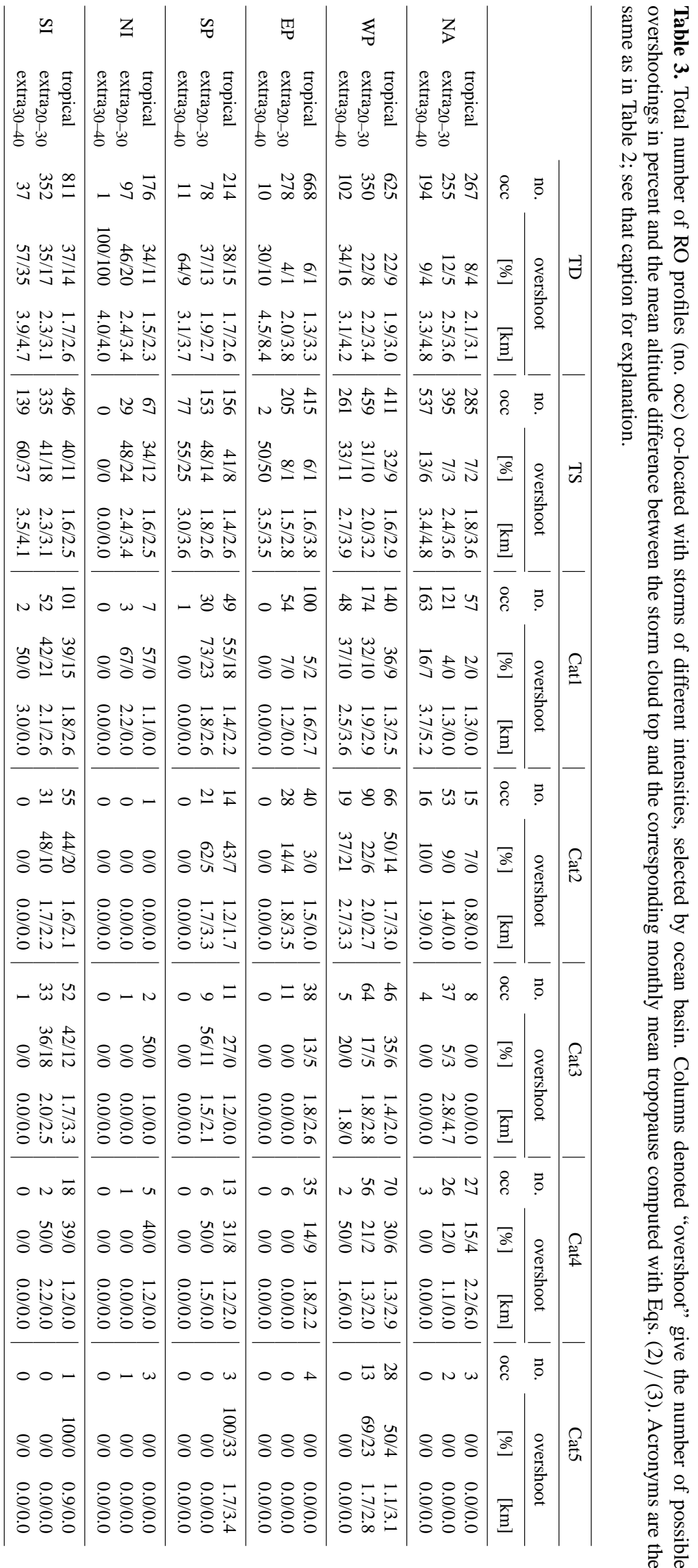


Table 4. Summary of Table 3, reporting the percentage of tropical and extratropical cases binned into ocean basins, hemispheres, and tropics/extratropics. The column "Percentage" reports the percentage of possible overshootings computed with Eq. (2) and within brackets the percentage of possible overshootings computed with Eq. (3).

\begin{tabular}{llrr}
\hline & & Total & Percentage \\
\hline \multirow{2}{*}{ North Atlantic Ocean } & tropical & 662 & $7.2(2.7)$ \\
& extra & 1806 & $10.7(4.4)$ \\
\hline \multirow{2}{*}{ Western Pacific Ocean } & tropical & 1386 & $29.2(8.9)$ \\
& extra & 1643 & $28.8(9.7)$ \\
\hline \multirow{2}{*}{ Eastern Pacific Ocean } & tropical & 1300 & $6.3(1.3)$ \\
& extra & 594 & $6.6(1.5)$ \\
\hline \multirow{2}{*}{ South Pacific Ocean } & tropical & 460 & $40.9(12.4)$ \\
& extra & 399 & $48.4(15.8)$ \\
\hline \multirow{2}{*}{ Northern Indian Ocean } & tropical & 261 & $34.5(10.7)$ \\
& extra & 133 & $46.6(20.3)$ \\
\hline \multirow{2}{*}{ Southern Indian Ocean } & tropical & 1534 & $38.3(12.8)$ \\
& extra & 1039 & $40.1(19.6)$ \\
\hline \multirow{2}{*}{ Northern Hemisphere } & tropical & 3609 & $20.2(6.2)$ \\
& extra & 7785 & $9.9(3.5)$ \\
\hline \multirow{2}{*}{ Southern Hemisphere } & tropical & 1994 & $38.9(12.6)$ \\
& extra & 2438 & $25.0(10.9)$ \\
\hline Tropical & & 5603 & $26.8(8.5)$ \\
\hline Extratropical & & 10223 & $13.5(5.3)$ \\
\hline
\end{tabular}

variability. Between 30 and $40^{\circ}$ latitude, the tropopause altitude ranges from 11 to $15 \mathrm{~km}$ (Fig. 1).

Figure 10 shows the difference between the cloud top altitude and the corresponding monthly mean tropopause (also reported in Table 3). The highest percentage of cases with differences larger than $3 \mathrm{~km}$ is detected for extratropical cases in the southern Indian Ocean basin. In general, in the North Atlantic Ocean and eastern Pacific Ocean basins the cloud top altitudes do not overpass the tropopause by more than a few hundred meters (green dots in Fig. 10).

Figure 11 shows, in a statistical summary view, an example of possible overshooting detection results in the western Pacific Ocean basin for TSs at different latitudes $\left(0-20^{\circ} ; 20\right.$ $30^{\circ} ; 30-40^{\circ}$ ), as reported in Table 3 . The magenta stars in the shaded area, according to Eqs. (2) and (3), denote the storm cloud top altitudes not overshooting into the stratosphere, the magenta stars in the white area account for possible overshooting according to Eq. (2), and the green stars account for possible overshooting according to Eq. (3). The distribution over the year shows that storms occur from April to December over the western Pacific Ocean at 0 to $20^{\circ} \mathrm{N}$ and mainly from July to October at 20 to $40^{\circ} \mathrm{N}$. Overshootings are found in each investigated latitude zone when storms occur. Hardly

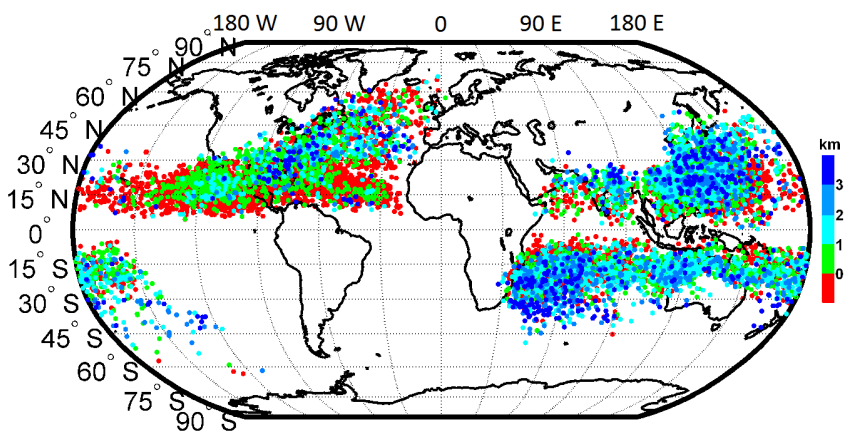

Figure 10. Distribution of the difference between the cloud top altitude and the tropopause altitude for all the GPS RO profiles colocated with TC best tracks.

any overshootings are found from July to September in the tropics $\left(0\right.$ to $\left.20^{\circ} \mathrm{N}\right)$.

\section{Conclusions}

The thermal structure of TCs in different ocean basins and the conditions for possible overshooting of cloud tops into the stratosphere, were investigated based on GPS RO measurements. The results indicate that the effects of TCs on the UTLS should be studied in connection to the ocean basin where they develop, since their thermal structure is clearly connected to the basin. In particular, basins in the Northern and Southern hemispheres show a different thermal structure:

In the Southern Hemisphere, storms reach higher altitudes and the cloud top is colder than in the Northern Hemisphere. The temperature anomaly above the cloud top becomes positive in Northern Hemisphere ocean basins while it stays negative up to about $25 \mathrm{~km}$ in altitude in the Southern Hemisphere ocean basins. The reason of this warming above the storm cloud top in the Northern Hemisphere is not clear yet and is a topic of further investigations.

A double tropopause characterizes a storm (Biondi et al., 2012, 2013), which is evident in all the ocean basins for all storm intensities (not shown) and can be definitely defined as a feature reflecting the high-altitude convection dynamics. Comparisons between the monthly mean tropopause altitude and the storm cloud top altitude indicate a significant fraction of possible overshootings. Results show that the possible overshootings will overpass the climatological tropopause more deeply at extratropical latitudes (Table 3), where the tropopause is lower, but there is no clear tendency connected to specific basins.

While the co-locations between GPS ROs and TC tracks for all the intensities are well distributed in all the ocean basins, conditions for overshooting occur more frequently in the Southern Hemisphere and in the northern Indian Ocean basin. However, the number of possible overshootings for high intensities (i.e., TC categories 1 to 5) is higher in the western Pacific Ocean basin. In this area, conditions for over- 

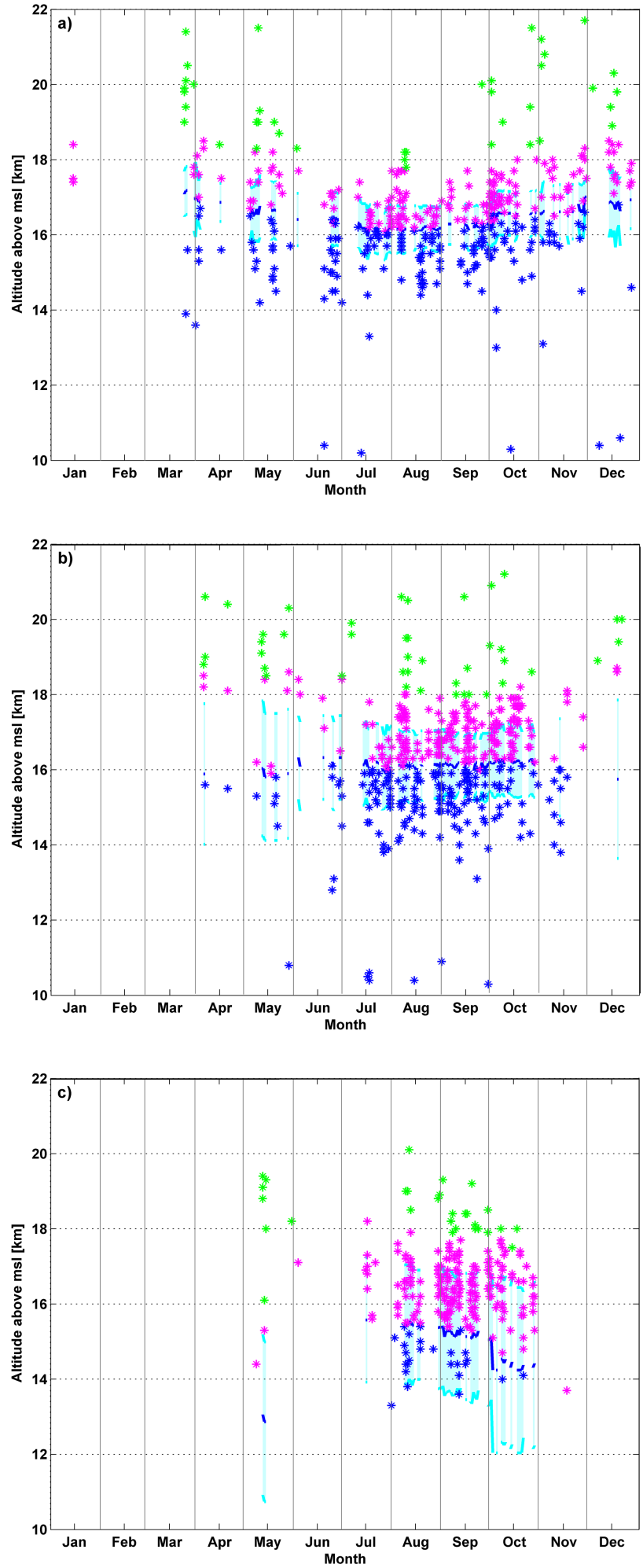

Figure 11. Monthly mean tropopause altitude (solid line) and standard deviation (light-blue shaded area) for different latitude zones (a) $0-20^{\circ}$, (b) $20-30^{\circ}$ and (c) $30-40^{\circ}$ in the western Pacific Ocean basin. The stars denote the storm cloud top altitudes below the mean tropopause (blue), above the tropopause (magenta) and for overshooting according to Eq. (2) (magenta with white background) and overshooting according to Eq. (3) (green), respectively. shooting are found for a percentage of 30 to $50 \%$ of the cyclones, especially within tropical latitudes.

We have demonstrated that the GPS RO technique is very well suited for monitoring and understanding the TCs' thermal structure and its contribution to the atmospheric circulation through possible overshootings into the stratosphere. With the actual RO missions we are not able to fully monitor all TCs with high temporal resolution. Currently, the number of RO profiles is decreasing due to the degradation of Formosat-3/COSMIC. In the near future several new missions are planned (e.g., COSMIC-2, MetOp-C, PAZ and GEROS), and with the support of new Global Navigation Satellite System (GNSS) constellations (e.g., the European Galileo) and the availability of the Russian Global'naya Navigatsionnaya Sputnikovaya Sistema (GLONASS), we may be able to adequately monitor all TCs.

To date the number of GPS ROs is about 2500 per day, but with the new mission COSMIC-2, for example, the coverage will increase to more than 10000 per day and the density of profiles in the tropics will be higher due to a lower inclination of six of the twelve planned COSMIC-2 satellites. This will definitely be an advantage for the study of TCs.

Acknowledgements. The research leading to these results has received funding from the People Programme (Marie Curie Actions) of the European Union's Seventh Framework Programme (FP7/2007-2013) under REA grant agreement no. 328233. UCAR is thanked for providing access to its $\mathrm{RO}$ orbit and excess phase data, ECMWF for access to its analysis and short-term forecast data, and WEGC for OPS development and provision of the most recent OPSv5.6 RO data.

Edited by: T. J. Dunkerton

\section{References}

Anthes, R. A.: Exploring Earth's atmosphere with radio occultation: contributions to weather, climate and space weather, Atmos. Meas. Tech., 4, 1077-1103, doi:10.5194/amt-4-1077-2011, 2011.

Anthes, R. A., Bernhardt, P. A., Chen, Y., Cucurull, L., Dymond, K. F., Ector, D., Healy, S. B., Ho, S.-H., Hunt, D. C., Kuo, Y.-H., Liu, H., Manning, K., McCormick, C., Meehan, T. K., Randel,W. J., Rocken, C., Schreiner,W. S., Sokolovskiy, S. V., Syndergaard, S., Thompson, D. C., Trenberth, K. E., Wee, T.-K., Yen, N. L., and Zeng, Z.: The COSMIC/Formosat/3 mission: Early results, B. Am. Meteorol. Soc., 89, 313-333, 2008.

Beyerle, G., Schmidt, T., Michalak, G., Heise, S., Wickert, J., and Reigber, C.: GPS radio occultation with GRACE: Atmospheric Profiling utilizing the zero difference technique, Geophys. Res. Lett., 32, L13806, doi:10.1029/2005GL023109, 2005. 
Biondi, R., Randel, W. J., Ho, S.-P., Neubert, T., and Syndergaard, S.: Thermal structure of intense convective clouds derived from GPS radio occultations, Atmos. Chem. Phys., 12, 5309-5318, doi:10.5194/acp-12-5309-2012, 2012.

Biondi, R., Ho, S. P., Randel, W., Syndergaard, S., and Neubert, T.: Tropical cyclone cloud-top height and vertical temperature structure detection using GPS radio occultation measurements, J. Geophys. Res. Atmos., 118, 5247-5259, doi:10.1002/jgrd.50448, 2013.

Brueske, K. F. and Velden, C. S.: Satellite based tropical cyclone intensity estimation using the NOAA-KLM series Advanced Microwave Sounding Unit (AMSU), Mon. Weather Rev., 131, 687-697, doi:10.1175/15200493(2003)131<0687:SBTCIE>2.0.CO;2, 2003.

Roy, C. and Kovordányi, R.: Tropical cyclone track forecasting techniques - A review, Atmos. Res., 104-105, 40-69, doi:10.1016/j.atmosres.2011.09.012, 2011.

Chang, F. L., Minnis, P., Ayers, J. K., McGill, M. J., Palikonda, R., Spangenberg, D. A., Smith Jr., W. L., and Yost, C. R.: Evaluation of satellite-based upper troposphere cloud top height retrievals in multilayer cloud conditions during TC4, J. Geophys. Res., 115, D00J05, doi:10.1029/2009JD013305, 2010.

Chiu, Y.-T.: Typhoon Haiyan: Philippines faces long road to recovery, The Lancet, 382, 1691-1692, doi:10.1016/S01406736(13)62380-6, 2013

Corti, T., Luo, B. P., deReus, M., Brunner, D., Cairo, F., Mahoney, M. J., Matucci, G., Matthey, R., Mitev, V., dos Santos, F. H., Schiller, C., Shur, G., Sitnikov, N. M., Spelten, N., Vossing, H. J., Borrmann, S., and Peter, T.: Unprecedented evidence for overshooting convection hydrating the tropical stratosphere, Geophys. Res. Lett., 35, L10810, doi:10.1029/2008GL033641, 2008.

Danielsen, E. F.: In situ evidence of rapid, vertical, irreversible transport of lower tropospheric air into the lower tropical stratosphere by convective cloud turrets and by larger-scale upwelling in tropical cyclones, J. Geophys. Res., 98, 8665-8681, doi:10.1029/92JD02954, 1993.

Davis, C. A., Ahijevych, D. A., Haggerty, J. A., and Mahoney, M. J.: Observations of Temperature in the Upper Troposphere and Lower Stratosphere of Tropical Weather Disturbances, J. Atmos. Sci., 71, 1593-1608, doi:10.1175/JAS-D-13-0278.1, 2014.

DeMaria, M., Mainelli, M., Shay, L. K., Knaff, J. A., and Kaplan, J.: Further improvements to the statistical hurricane intensity prediction scheme (SHIPS), Weather Forecast., 20, 531-543, doi:10.1175/WAF862.1, 2005

Demuth, J. L., DeMaria, M., and Vonder Haar, T. H.: Evaluation of Advanced Microwave Sounding Unit tropical-cyclone intensity and size estimation algorithm, J. Appl. Meteorol., 43, 282-296, doi:10.1175/1520-0450(2004)043<0282:EOAMSU>2.0.CO;2, 2004.

Dvorak, V. F.: Tropical cyclone intensity analysis and forecasting from satellite imagery, Mon. Weather Rev., 103, 420-430, doi:10.1175/1520-0493(1975)103<0420:TCIAAF>2.0.CO;2, 1975.

Emanuel, K. A.: Thermodynamic control of hurricane intensity, Nature, 401, 665-669, doi:10.1038/44326, 1999.

Emanuel, K. A.: Increasing destructiveness of tropical cyclones over the past 30 years, Nature, 436, 686-688, doi:10.1038/nature03906, 2005.
Emanuel, K. A.: Downscaling CMIP5 climate models shows increased tropical cyclone activity over 21 st century, P. Natl. Acad. Sci. USA, 110, 12219-12224, 2013.

Emanuel, K., Ragoth, S., and John, W.: Hurricanes and global warming: results from downscaling ipcc ar4 simulations, B. Am. Meteorol. Soc., 89, 347-367, doi:10.1175/BAMS-89-3-347, 2008.

Folkins, I. and Martin, R. V.: The Vertical Structure of Tropical Convection and Its Impact on the Budgets of Water Vapor and Ozone, J. Atmos. Sci., 62, 1560-1573, doi:10.1175/JAS3407.1, 2005.

Goerss, J. S.: Tropical Cyclone Track Forecasts Using an Ensemble of Dynamical Models, Mon. Weather Rev., 128, 1187-1193, doi:10.1175/1520-0493(2000)128<1187:TCTFUA>2.0.CO;2, 2000.

Gorbunov, M. E., Benzon, H.-H., Jensen, A. S., Lohmann, M. S., and Nielsen, A. S.: Comparative analysis of radio occultation processing approaches based on Fourier integral operators, Radio Sci., 39, RS6004, doi:10.1029/2003RS002916, 2004.

Hajj, G. A., Ao, B. A., Iijima, B. A., Kuang, D., Kursinski, E. R., Mannucci, A. J., Meehan, T. K., Romans, L. J., de la Torre Juarez, M., and Yunck, T. P.: CHAMP and SAC-C atmospheric occultation results and intercomparisons, J. Geophys. Res., 109, D06109, doi:10.1029/2003JD003909, 2004.

Halverson, J. B. and Rabenhorst, R.: Hurricane Sandy: The Science and Impacts of a Superstorm, Weatherwise, 66, 14-23, doi:10.1080/00431672.2013.762838, 2013.

Holloway, C. E. and Neelin, J. D.: The Convective Cold Top and Quasi Equilibrium, J. Atmos. Sci., 64, 1467-1487, doi:10.1175/JAS3907.1, 2007.

Huang, C.-Y., Kuo, Y.-H., Chen, S.-H., and Vandenberghe, F.: Improvements in Typhoon Forecasts with Assimilated GPS Occultation Refractivity, Weather Forecast., 20, 931-953, doi:10.1175/WAF874.1, 2005.

Kiladis, G., Straub, K., Reid, G., and Gage, K.: Aspects of interannual and intraseasonal variability of the tropopause and lower stratosphere, Q. J. R. Meteorol. Soc., 127, 1961-1983, doi:10.1002/qj.49712757606, 2001.

Kim, J.-E. and Alexander, M. J.: Direct impacts of waves on tropical cold point tropopause temperature, Geophys. Res. Lett., 42 1584-1592, doi:10.1002/2014GL062737, 2015.

Knapp, K. R., Kruk, M. C., Levinson, D. H., Diamond, H. J., and Neumann, C. J.: The International Best Track Archive for Climate Stewardship (IBTrACS): Unifying tropical cyclone best track data, B. Am. Meteorol. Soc., 91, 363-376, doi:10.1175/2009BAMS2755.1, 2010.

Knibbe, W. J. J., de Haan, J. F., Hovenier, J. W., Stam, D. M., Koelemeijer, R. B. A., and Stammes, P.: Deriving terrestrial cloud top pressure from photopolarimetry of reflected light, J. Quant. Spectrosc. Ra., 64, 173-199, doi:10.1016/S0022-4073(98)00135-6, 2000.

Koelemeijer, R. B. A., Stammes, P., Hovenier, J. W., and de Haan, J. F.: Global distributions of effective cloud fraction and cloud top pressure derived from oxygen A band spectra measured by the global ozone monitoring experiment: Comparison to ISCCP data, J. Geophys. Res., 107, AAC 5-1-AAC 5-9, doi:10.1029/2001JD000840, 2002.

Kunkel, K. E., Karl, T. R., Brooks, H., Kossin, J., Lawrimore, J. H., Arndt, D., Bosart, L., Changnon, D., Cutter, S. L., Doesken, N., 
Emanuel, K., Groisman, P. Y., Katz, R. W., Knutson, T., O’Brien, J., Paciorek, C.-J., Peterson, T. C., Redmond, K., Robinson, D., Trapp, J., Vose, R., Weaver, S., Wehner, M., Wolter, K., and Wuebbles, D.: Monitoring and understanding changes in extreme storms: State of knowledge, B. Am. Meteorol. Soc., 94, 499-514, doi:10.1175/BAMS-D-12-00066.1, 2013.

Kursinski, E. R., Hajj, G. A., Schofield, J. T., Linfield, R. P. and Hardy, K. R.: Observing Earth's atmosphere with radio occultation measurements using the Global Positioning System, J. Geophys. Res., 102, 23429-23465, doi:10.1029/97JD01569, 1997.

Landsea, C. W., Harper, B. A., Hoarau, K., and Knaff, J. A.: Climate change. Can we detect trends in extreme tropical cyclones?, Science, 313, 452-454, 2006.

Lin, I.-I., Goni, G. J., Knaff, J. A., Forbes, C., and Ali, M. M.: Ocean heat content for tropical cyclone intensity forecasting and its impact on storm surge, Nat. Hazards, 66, 1481-1500, doi:10.1007/s11069-012-0214-5, 2013.

Luo, Z., Stephens, G. L., Emanuel, K. A., Vane, D. G., Tourville, N. D., and Haynes, J. M.: On the use of CloudSat and MODIS data for estimating hurricane intensity, IEEE Geosci. Remote Sens. Lett., 5, 13-16, doi:10.1109/LGRS.2007.905341, 2008.

Melbourne, W. G., Davis, E. S., Duncan, C. B., Hajj, G. A., Hardy, K. R., Kursinski, E. R., Meehan, T. K., Young, L. E., and Yunck, T. P.: The application of spaceborne GPS to atmospheric limb sounding and global change monitoring, NASA technical report, NASA-CR-199799, NAS 1.26:199799, JPL-PUBL-94-18, NIPS-95-06497, Jet Propulsion Lab., California Inst. of Tech., Pasadena, CA, USA, 1994.

Mendelsohn, R., Emanuel, K., Chonabayashi, S., and Bakkensen, L.: The impact of climate change on global tropical cyclone damage, Nature Clim. Change, 2, 205-209, doi:10.1038/nclimate1357, 2013.

Minnis, P., Yost, C. R., Sun-Mack, S., and Chen, Y.: Estimating the top of the cloud of optically thick ice clouds from thermal infrared satellite observations using CALIPSO data, Geophys. Res. Lett., 35, L12801, doi:10.1029/2008GL033947, 2008.

Montgomery, M. T., Davis, C., Dunkerton, T., Wang, Z., Velden, C., Torn, R., Majumdar, S. J., Zhang, F., Smith, R. K., Bosart, L., Bell, M. M., Haase, J. S., Heymsfield, A., Jensen, J., Campos, T., and Boothe, M. A.: The Pre-Depression Investigation of CloudSystems in the Tropics (PREDICT) Experiment: Scientific Basis, New Analysis Tools, and Some First Results, B. Am. Meteorol. Soc., 93, 153-172, doi:10.1175/BAMS-D-11-00046.1, 2012.

Pielke, R., Rubiera, J., Landsea, C., Fernández, M., and Klein, R.: Hurricane Vulnerability in Latin America and The Caribbean: Normalized Damage and Loss Potentials, Natural Hazards Review, 4, 101-114, doi:10.1061/(ASCE)15276988(2003)4:3(101), 2003.

Platnick, S., King, M. D., Ackerman, S. A., Menzel, W. P., Baum, B. A., Riedi, J. C., and Frey, R. A.: The MODIS cloud products: Algorithms and examples from Terra, IEEE Trans. Geosci. Remote Sens., 41, 459-473, doi:10.1109/TGRS.2002.808301, 2003.

Pommereau, J.-P. and Held, G.: Is there a stratospheric fountain?, Atmos. Chem. Phys. Discuss., 7, 8933-8950, doi:10.5194/acpd7-8933-2007, 2007.

Poole, L. R., Winker, D. M., Pelon, J. R., and McCormick, M. P.: CALIPSO: GLOBAL aerosol and cloud observations from lidar and passive instruments, Proc. SPIE, 481, 419-426, doi:10.1117/12.462519, 2002.
Randel, W. J., Wu, F., and Rios, W. R.: Thermal variability of the tropical tropopause region derived from GPS/MET observations, J. Geophys. Res., 108, 1-12, doi:10.1029/2002JD002595, 2003.

Ray, E. A. and Rosenlof, K. H.: Hydration of the upper tropopsphere by tropical cyclones, J. Geophys. Res., 112, D12311, doi:10.1029/2006JD008009, 2007.

Rieckh, T., Scherllin-Pirscher, B., Ladstädter, F., and Foelsche, U.: Characteristics of tropopause parameters as observed with GPS radio occultation, Atmos. Meas. Tech., 7, 3947-3958, doi:10.5194/amt-7-3947-2014, 2014.

Romps, D. M. and Kuang, Z.: Overshooting convection in tropical cyclones, Geophys. Res. Lett., 36, L09804, doi:10.1029/2009GL037396, 2009.

Scherllin-Pirscher, B., Steiner, A. K., Kirchengast, G., Kuo, Y.-H., and Foelsche, U.: Empirical analysis and modeling of errors of atmospheric profiles from GPS radio occultation, Atmos. Meas. Tech., 4, 1875-1890, doi:10.5194/amt-4-1875-2011, 2011.

Schwaerz, M., Scherllin-Pirscher, B, Kirchengast, G., Schwarz, J., Ladstaedter, F., Fritzer, J., and Ramsauer, J.: Multi-mission validation by satellite radio occultation, ESA report, WEGC-ESAMMvalRO-2013-FR, 2013.

Sherwood, S. C., Minnis, P., McGill, M., and Chae J. C.: Underestimation of deep convective cloud tops by thermal imagery, Geophys. Res. Lett., 31, L11102, doi:10.1029/2004GL019699, 2004.

Steiner, A. K., Lackner, B. C., Ladstädter, F., Scherllin-Pirscher, B., Foelsche, U., and Kirchengast, G.: GPS radio occultation for climate monitoring and change detection, Radio Science, 46, RS0D24, doi:10.1029/2010RS004614, 2011.

Steiner, A. K., Hunt, D., Ho, S.-P., Kirchengast, G., Mannucci, A. J., Scherllin-Pirscher, B., Gleisner, H., von Engeln, A., Schmidt, T., Ao, C., Leroy, S. S., Kursinski, E. R., Foelsche, U., Gorbunov, M., Heise, S., Kuo, Y.-H., Lauritsen, K. B., Marquardt, C., Rocken, C., Schreiner, W., Sokolovskiy, S., Syndergaard, S., and Wickert, J.: Quantification of structural uncertainty in climate data records from GPS radio occultation, Atmos. Chem. Phys., 13, 1469-1484, doi:10.5194/acp-13-1469-2013, 2013.

Tsuda, T., Nishida, M., Rocken, K., and Ware, R. H.: A global morphology of gravity wave activity in the stratosphere revealed by the GPS occultation data (GPS/MET), J. Geophys. Res., 105, 7257-7273, doi:10.1029/1999JD901005, 2000.

Velden, C. S., Harper, B., Wells, F., Beven II, J. L., Zehr, R., Olander, T., Mayfield, M., Guard, C., Lander, M., Edson, R., Avila, L., Burton, A., Turk, M., Kikuchi, A., Christian, A., Caroff, P., and McCrone, P.: The Dvorak tropical cyclone intensity estimation technique: A satellite-based method that has endured for over 30 years, B. Am. Meteorol. Soc., 87, 1195-1210, doi:10.1175/BAMS-87-9-1195, 2006.

Vergados P., Luo, Z.-J., Emanuel, K., and Mannucci A. J.: Observational tests of hurricane intensity estimation using GPS radio occultations, J. Geophys. Res. Atmos., 119, 1936-1948, doi:10.1002/2013JD020934, 2013.

Wickert, J., Reigber, C., Beyerle, G., König, R., Marquardt, C., Schmidt, T., Grundwaldt, L., Galas, R., Meehan, T. K., Melbourne, W. G., and Hocke, K.: Atmosphere sounding by GPS radio occultation: First results from CHAMP, Geophys. Res. Lett., 28, 3263-3266, 2001. 
WMO: Meteorology -A three-dimensional science: Second session of the commission for aerology, WMO Bulletin, 4, 134-138, 1957.
Wong V. and Emanuel, K. A.: Use of cloud radars and radiometers for tropical cyclone intensity estimation, Geophys. Res. Lett., 34, 12, L12811, doi:10.1029/2007GL029960, 2007. 